\title{
Alterations in fillet fatty acid profile and flesh quality in gilthead seabream (Sparus aurata) fed vegetable oils for a long term period. Recovery of fatty acid profiles by fish oil feeding
}

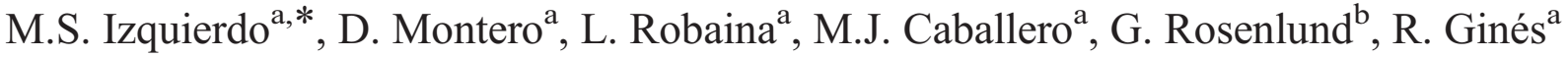 \\ ${ }^{\mathrm{a}}$ Grupo de Investigación en Acuicultura, ULPGC and ICCM. P.O. Box 56, 35200, Telde, Las Palmas, Canary Islands, Spain \\ ${ }^{\mathrm{b}}$ Nutreco Aquaculture Research Centre A/S, P.O. Box 48, N-4001 Stavanger, Norway
}

Received 18 August 2004; received in revised form 30 November 2004; accepted 1 December 2004

\begin{abstract}
To determine the effect of long term feeding of diets with high levels of vegetable oils gilthead seabream juveniles were fed for 7 months with several diets containing vegetable oils at two inclusion levels. Anchovy oil was the only lipid source of FO (fish oil) diet, whereas in diets 60RO, 60LO and 60SO, 60\% of fish oil was substituted by rapeseed (RO), linseed (LO) or soybean (SO) oils, respectively, and $80 \%$ was substituted by linseed or soybean oils in diets $80 \mathrm{LO}$ and $80 \mathrm{SO}$. Afterwards, all fish were fed only a fish oil diet to determine the progressive evolution of fillet fatty acid profiles, since fish muscle fatty acid composition changes by feeding vegetable oils affecting its nutritional value for human health.

Results showed that substitution by vegetable oils of up to $60 \%$ fish oil in diets for gilthead seabream does not affect growth and feed utilization even after a long feeding period. However, $80 \%$ substitution of fish oil significantly reduced growth. Feeding vegetable oils reduced muscle contents of docosahexaenoic acid (DHA) and arachidonic acid (ARA) to a lower degree than their reduction in the diet, denoting their importance, reduction of eicosapentaenoic acid (EPA) in muscle being more pronounced. Moreover, re-feeding with a FO diet for 60 days effectively recovered muscle DHA and ARA contents, whereas those of EPA were not recovered even after 90 days. Linoleic acid was strongly retained even after "wash out". Fish fillets were very well accepted by the panel of judges. Dietary soybean oil inclusion produced significantly less shiny and less hard fillets, but more juicy and adhesive than FO fillets, with a slight earthy flavour when fish were fed 80 SO diet. However linseed oil inclusion only increased shininess when fish were fed 80LO diet. A significantly higher chroma value was obtained for 80LO fish fillets, although it was not noticeable to the human eye.
\end{abstract}

(c) 2004 Elsevier B.V. All rights reserved.

Keywords: Fish oil; Vegetable oils; DHA; EPA; n-3 HUFA; Sparus aurata

Abbreviations: ARA, arachidonic acid (20:4 n-6); CI, conversion index; DHA, docosahexaenoic acid (22:6n-3); EFA, essential fatty acids; EPA, eicosapentaenoic acid (20:5 n-3); FO, fish oil; HUFA, Highly unsaturated fatty acids; LO, linseed oil; NL, Neutral lipids; OA, oleic acid (18:1 n-9); PL, polar lipids; RO, rapeseed oil; SGR, specific growth rate; SO, soybean oil.

* Corresponding author. Tel.: +34928132900; fax: +34928132908 .

E-mail address: mizquierdo@dbio.ulpgc.es (M.S. Izquierdo). 


\section{Introduction}

Even the most optimistic projections foresee that in a few years global production of fish oil (FO) (1.2-1.4 millions tons/year) may not be enough to cover its increasing demand for animal feeds, whereas vegetable oil production steadily increases and prices remain constant. Therefore there is considerable interest in the substitution of fish oil by vegetable oils in fish diets (Hardy et al., 2001). Some vegetable oils such as soybean and linseed oils are considered as good alternative lipid sources in salmonids and freshwater fish feeds (Bell et al., 2001;Rosenlund et al., 2001; Caballero et al., 2002). However, in marine fish feeds the use of vegetable oils as a sole lipid source is limited by the low ability of these species to convert linoleic and linolenic acids, abundant in many vegetable oils, into arachidonic (ARA), eicosapentaenoic (EPA) and docosahexaenoic acids (DHA) which are essential for marine fish and high in fish oil. For that reason, partial replacement of fish oil by vegetable oils would be only possible when these fatty acids are present in the diets in sufficient quantities to meet the essential fatty acid requirements. For instance, up to $60 \%$ fish oil may be replaced by palm oil in diets for yellowtail without altering fish growth, but reducing "in vivo" peroxidation (Watanabe, 2002). Although fish oil replacements by vegetable oils higher than $50 \%$ significantly reduce seabream growth when the dietary lipid level is as low as $10-12 \%$ (Alexis, 1997), feeding a high lipid content diet allows replacement of up to $60 \%$ of the fish oil by several vegetable oils without compromising seabream or sea bass growth and feed utilisation (Izquierdo et al., 2003), since the portion of fish oil included is able to meet the essential fatty acid (EFA) requirements of these species. Nevertheless, after three months of feeding high lipid diets with a $60 \%$ fish oil replacement by certain vegetable oils, particularly soybean oil, liver lipid content and lipid deposition in the hepatocytes markedly increased (Caballero, 2002) and some immune parameters were affected (Montero et al., 2003) suggesting undesirable effects on fish health when longer feeding periods are tested.

Inclusion of vegetable oils in fish diets also modifies body fatty acid profiles and may significantly affect fish flesh quality and sensory character- istics (Guillou et al., 1995; Morris et al., 1995). In previous studies (Izquierdo et al., 2003), very good acceptance of fillets from seabream fed vegetable oils was shown by a trained taste panel and fillets were not judged as significantly different from fish fed fish oil alone. However, it would be necessary to confirm if growth and fillet taste and texture is still not affected when seabream are fed higher levels of vegetable oils or during longer periods of time.

Modification of fatty acid profiles in fish fillets included the reduction in the n-3 highly unsaturated fatty acids (HUFA), and particularly in eicosapentaenoic acid (EPA) (Izquierdo et al., 2003). Consumption of food rich in n-3 HUFA like fish, has a positive effect on human health (Ackman, 2001), such as prevention of cardiovascular pathologies (Herold and Kinsella, 1986), and auto-immune diseases (Hwang, 1989). For this reason, it is advantageous to use fish oils very rich in n-3 HUFA such as Peruvian anchovy oil (Rosenlund et al., 2001), which would allow a higher replacement by vegetable oils, producing fish fillets with a similar n-3 HUFA content than fish fed $100 \%$ menhaden fish oil. Nevertheless, since it is desirable to produce fish fillets with the highest content in these fatty acids to promote its beneficial effects for human nutrition, feeding the last period of on-growing with $100 \%$ fish oil diets may enable a recovery of the n-3 HUFA levels in fillets of fish previously fed vegetable oils.

The objective of this study was to determine the effect of long term feeding diets with high levels of vegetable oil on growth performance and flesh quality of gilthead seabream, and the progressive evolution of fillet fatty acid profiles when fish were fed a fish oil diet during the last part of the on-growing period.

\section{Materials and methods}

Gilthead seabream (Sparus aurata) juveniles (85 g initial body weight) were distributed in 18 tanks of 5001 (65 fish/tank, each diet assayed in triplicate) supplied with seawater at a temperature ranging from $19.5^{\circ} \mathrm{C}$ at the beginning of the experiment to $23.8^{\circ} \mathrm{C}$ at the end, and aeration. Fish were fed the experimental diets (Table 1) until apparent satiation (3 times/day, 6 days/week), until they reached the commercial size after 204 days. Six iso-energetic 
Table 1

Ingredients ( $\mathrm{g} / \mathrm{kg})$ and chemical composition (\% dry basis) of the experimental diets containing different lipid sources

\begin{tabular}{|c|c|c|c|c|c|c|}
\hline \multirow[t]{2}{*}{ Ingredient } & \multicolumn{6}{|l|}{ Diet } \\
\hline & FO & $60 \mathrm{SO}$ & $60 \mathrm{RO}$ & $60 \mathrm{LO}$ & $80 \mathrm{SO}$ & $80 \mathrm{LO}$ \\
\hline Fish meal (LT) & 381.3 & 381.3 & 381.3 & 381.3 & 381.3 & 381.3 \\
\hline Corn gluten & 259.8 & 259.8 & 259.8 & 259.8 & 259.8 & 259.8 \\
\hline Wheat & 150.7 & 150.7 & 150.7 & 150.7 & 150.7 & 150.7 \\
\hline Lysine $(99 \%)$ & 7.2 & 7.2 & 7.2 & 7.2 & 7.2 & 7.2 \\
\hline Premix $^{a}$ & 25 & 25 & 25 & 25 & 25 & 25 \\
\hline Anchovy oil & 176 & 70.4 & 70.4 & 70.4 & 35.2 & 35.2 \\
\hline Soybean oil ${ }^{\mathrm{b}}$ & & 105.6 & & & 140.8 & \\
\hline Rapeseed oil ${ }^{\mathrm{b}}$ & & & 105.6 & & & \\
\hline Linseed oil ${ }^{\mathrm{b}}$ & & & & 105.6 & & 140.8 \\
\hline \multicolumn{7}{|l|}{ Composition } \\
\hline Crude lipids & 23.74 & 24.15 & 22.94 & 23.19 & 22.59 & 25.48 \\
\hline Crude protein & 47.52 & 48.84 & 48.51 & 48.52 & 49.43 & 48.71 \\
\hline
\end{tabular}

and isonitrogenous diets with a lipid content of about $22 \%$ were formulated. Anchovy oil was the only added lipid source in Diet FO (fish oil). All the other diets contained vegetable oils: to substitute either $60 \%$ of the anchovy by soybean oil (SO) in $\operatorname{diet} 60 \mathrm{SO}$, by rapeseed oil (RO) in 60RO and by linseed oil (LO) in $60 \mathrm{LO}$ or $80 \%$ in diets $80 \mathrm{SO}$ (soybean oil) and $80 \mathrm{LO}$ (linseed oil). Fish oil was included in diets 60SO, 60RO and 60LO at a level high enough to cover the EFA requirements of this species.

Feed intake was determined daily and all fish were individually weighed monthly. Conversion index (CI), and specific growth rate (SGR) were calculated using the following formulae: $\mathrm{CI}=$ feed intake/weight gain, $\mathrm{SGR}=((\mathrm{Ln}$ final weight $-\mathrm{Ln}$ initial weight $) / \mathrm{t}) * 100$, $t=$ experimental period (days). Mortalities were daily recorded and survival was monthly determined.

After 81 and 204 days of feeding, samples from muscle of 18 fish fed each experimental diet were collected, immediately frozen and kept under $-80{ }^{\circ} \mathrm{C}$ until they were analysed. Lipids from diets and muscle were extracted with a chloroform:methanol (2:1 v:v) mixture (Folch et al., 1957). The fatty acid methyl esters were obtained by transesterification with $1 \%$ sulphuric acid in methanol (Christie, 1982) and purified by absorption chromatography on $\mathrm{NH}_{2}$ Seppak cartridges (Waters, S.A., Milford, Massachusetts) and separated and quantified by gas-liquid chroma- tography under the conditions previously described (Izquierdo et al., 1990). Fatty acid methyl esters were identified by comparison to external standards.

Organoleptic tests were conducted with fillets cooked for $10 \mathrm{~min}$ in a steam oven $\left(150{ }^{\circ} \mathrm{C}\right)$ from fish which had been previously starved for $24 \mathrm{~h}$ before being slaughtered in a small tank with ice and seawater. A total of 9 fish from each treatment were chosen at random, gutted, filleted and kept at $4{ }^{\circ} \mathrm{C}$ for $24 \mathrm{~h}$ until tests were carried out. Immediately after cooking in aluminum boxes, fillets were offered to a panel of 12 selected and trained judges (ISO, 1985, 1993). Tests were conducted in isolated and air conditioned rooms with standardized light (ISO, 1988). Judges were randomly offered closed food boxes labelled with codes containing the fillets $(3 \times 4$ $\mathrm{cm})$. Odour (freshness, earthy, off-odour and oily), appearance (exuded, flaked, shininess and colour), texture (adhesiveness, hardness, firmness and juiciness), flavour (freshness, earthy, off-flavour and oily) and residual taste (persistence, earthy and oily) were tested for samples of fish fed the experimental diets and classified by the judge in a continuous scale from 0 to 100 for each parameter. A 4465 INSTRON UTM texture analyser (Instrom Canton, MS, USA) was used to determine the texture of fish fillets. All tests were carried out at refrigeration temperature, keeping both the fish and the fillet cooled with ice. The whole fish were compressed using a cylinder of $1.2 \mathrm{~cm}$ diameter at a speed of $50 \mathrm{~mm} / \mathrm{min}$ and the force required to penetrate the dorsal zone of the right-hand side of the fish to a depth of $4 \mathrm{~mm}$ was measured (Ginés et al., 2002). Fish fillets were compressed and punctured following the methodology described by Borderías et al. (1983). For the puncture tests, cylindrical pieces of fillet of $5.3 \mathrm{~cm}$ in diameter and $1.2 \mathrm{~cm}$ in height were cut from the fish left upper flank. Flesh puncture was measured after the fillet had been completely penetrated by a $0.8 \mathrm{~cm}$ wide cylinder at a speed of 80 $\mathrm{mm} / \mathrm{min}$. Similarly, for the compression tests, cylindrical pieces of fillet of $2.6 \mathrm{~cm}$ wide and $1.2 \mathrm{~cm}$ high were cut from the fish left flank. The flesh compression was measured as the force required to compress the thickness of the fillet by $30 \%$ using a $3.6 \mathrm{~cm}$ wide cylindrical piston at a speed of $50 \mathrm{~mm} / \mathrm{min}$. Instrumental colour analysis was performed with a MINOLTA CHROMAMETER CR200 (Minolta, Osaka, Japan) giving results in CIE (1976) values for 
lightness $\left(\mathrm{L}^{*}\right)$, associated with the brightness intensity of the stimulus, chroma $\left(\left(\mathrm{a}^{*^{2}+\mathrm{b}^{* 2}}\right)^{1 / 2}\right)$, in relation with the proportion of pure colour, and the angle of hue $\left(\tan ^{-1}\left(\mathrm{~b}^{*} / \mathrm{a}^{*}\right)\right)$ pertaining to the predominant colour (Wyszecki and Stiles, 1982). The $\mathrm{pH}$ of the flesh was determined using a Crison penetration electrode (accurate to $0.01 \mathrm{pH}$ unit, model 507; Crison Instruments S.A., Barcelona, Spain) after carrying out an incision on the skin.

Since the fatty acid composition of fish muscle affects its nutritional value for human health, a refeeding experiment with fish fed on selected diets was conducted. Thus, after sampling fish for growth performance, chemical composition and flesh quality, all the remaining fish previously fed diets $\mathrm{FO}, 60 \mathrm{SO}$, 60LO, 60RO and 80LO were fed diet FO for 95 days (wash out phase); this experiment could not be performed on $80 \mathrm{SO}$ fish which were lost in an accident. During this "wash out phase" fish were sampled after 35, 65, 80 and 95 days to follow the progress of fish fillets fatty acid profile. At each sampling point, 9 fish per treatment were sampled and pooled in 3 samples of 3 fish each. Samples of flesh were analysed for lipid content and fatty acid composition as described above. Samples of muscle from 10 wild seabream caught during the spring time along North West African cost and provided by professional fisherman were also analysed for lipid content and fatty acid composition.

All the data was statistically treated using ANOVA and Tukeýs test at $P<0.05$ was applied as a multiple sample comparison analysis (Sokal and Rolf, 1995) using a SPSS Statistical Software System ver 10.0 (SPSS Chicago, Illinois, 1999). In order to show the multivariate structure of the sensory evaluation, a principal component analysis (PCA) was conducted in Unscrambleri ${ }^{\circledR}$ version 7.5 program (Camo A/S, Oslo, Norway, 2000).

\section{Results}

Fatty acid analysis of dietary total lipids reflected the addition of the plant oils and their main composition is shown as wt.\% of total fatty acids in Fig. 1. Total saturated fatty acids ranged from $15.26 \%$ in diet $80 \mathrm{LO}$ to $28.31 \%$ in diet FO. Total monoenoic fatty acids (mainly oleic acid (OA), 18:1n-9) ranged from $13.65 \%$ in diet FO to $37.1 \%$ in diet $60 \mathrm{RO}$. Linoleic acid (18:2n-6) increased with plant oils addition,

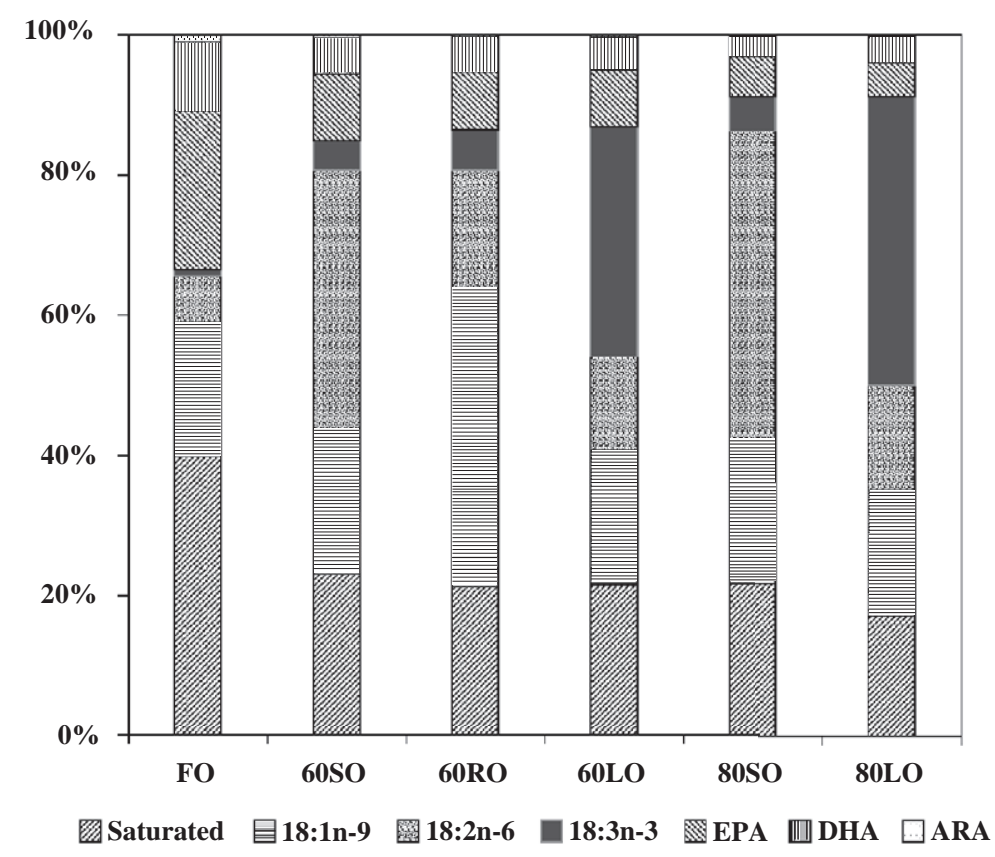

Fig. 1. Some fatty acids of the experimental diets ( $g / 100 \mathrm{~g}$ fatty acids). 
particularly with the increasing inclusion of soybean oil, from $4.7 \%$ in diet $\mathrm{FO}$ to $38.52 \%$ in diet $80 \mathrm{SO}$. Similarly, linolenic acid (18:3n-3) increased, particularly with the increasing inclusion of linseed oil, from $0.64 \%$ in diet FO to $36.67 \%$ in diet $80 \mathrm{LO}$. Percentages of EPA ranged from $16.16 \%$ in diet $\mathrm{FO}$ to $4.3 \%$ in diet 80LO, while docosahexaenoic acid (DHA) ranged from $7.01 \%$ in diet FO to $2.44 \%$ in $\operatorname{diet} 80 \mathrm{SO}$. Thus, in diets with a $60 \%$ fish oil substitution by plant oils the contents of arachidonic acid (ARA), EPA and DHA were reduced by 53,55 and $42 \%$ compared to their respective values in diet $\mathrm{FO}$, whereas in diets with an $80 \%$ substitution the contents of these fatty acids were reduced by 63,71 and $59 \%$ compared to their respective values in diet FO.

All diets were well accepted by gilthead seabream and subsequently no significant differences were found in feed intake along the experimental period. At the beginning of the trial, gilthead seabream grew well regardless of the diet fed. Monthly specific growth rates (SGR) varied along the experiment from $0.92 \%$ /day for FO fish during the first month to $0.34 \%$ / day for 80LO fish during the last month, whereas feed conversion ratio ranged from 1.13 for FO diet during the first month to 2.01 for $80 \mathrm{SO}$ diet during the last month. After 159 days of feeding, substitution of $80 \%$ dietary fish oil by either soybean or linseed oils (80SO and 80LO) significantly $(P<0.05)$ reduced growth in comparison with fish fed the FO diet, both in terms of body weight, \% weight gain and SGR. Thus, average values for the whole feeding period for these three parameters were significantly lower for $80 \mathrm{SO}$ and 80LO fish as shown in Table 2. On the contrary, $60 \%$ substitution of fish oil by any of the three vegetable oils assayed did not significantly reduce growth performance in comparison with fish fed FO diet (Table 2). In agreement with the feed intake and growth results, $80 \mathrm{SO}$ and $80 \mathrm{LO}$ the conversion indexes for fish fed diets $80 \mathrm{SO}$ and $80 \mathrm{LO}$ were significantly $(P<0.05)$ higher than for fish fed diet FO.

Muscle fatty acid composition of total lipids showed the effect of the diets from the intermediate sampling (81 days of feeding, Table 3). Saturated fatty acids were reduced by the inclusion of dietary plant oils in the intermediate sampling and remained in similar levels until the end of feeding the vegetable oils (204 days, Table 4). However, this reduction of saturated fatty acids in the flesh (about 20\%) was smaller than the difference among diets (about 30\%). Monoenoic fatty acids and particularly oleic acid increased in the muscle of the fish fed diet 60RO in the intermediate sampling (Table 3) and continued increasing (10\% increase from the intermediate period) in the final sampling (Table 4). Linolenic acid increased along the first period in diets $60 \mathrm{LO}$ and $80 \mathrm{LO}$ (Table 3) proportionally to their levels in the diets but did not further increase in the final sampling (Table 4, Fig. 2). Linoleic acid increased in fish muscle with the inclusion of vegetable oils, particularly with soy bean oil, being 4 and 4.9 times higher in fish fed $60 \mathrm{SO}$ and $80 \mathrm{SO}$ than in FO fish (Table 3), and further increasing up to 4.28 and 5.12 times at the end of the experiment (Table 4, Fig. 3). Replacement of $60 \%$ dietary fish oil reduced n-3 HUFA muscle contents in the first sampling by $42 \%$, whereas $80 \%$ replacement reduced them by $53 \%$. The levels of these fatty acids were further reduced until the end of the experimental period reaching $47 \%$ and $60 \%$ reductions in fish fed $60 \%$ and $80 \%$ vegetable oil replacement, in comparison with fish fed FO diet. Reduction of these fatty acids along the experiment was more pronounced for EPA $(53 \%$ and $67 \%$ for fish fed $60 \%$ and $80 \%$ replacement) than for DHA (32\% and $40 \%$ ) or ARA ( $42 \%$ and $50 \%$ ) both in the intermediate and in the final sampling (60\% and $74 \%$ reduction for EPA, $35 \%$ and $46 \%$ for DHA and $43 \%$ and $54 \%$ for ARA) (Tables 3

Table 2

Growth and efficiency in utilization of feed by gilthead seabream fed different vegetable lipid sources (mean \pm SD)

\begin{tabular}{lllllll}
\hline & Diet & & & \\
\cline { 2 - 6 } & FO & $60 \mathrm{SO}$ & $60 \mathrm{RO}$ & $60 \mathrm{LO}$ & $80 \mathrm{SO}$ & $80 \mathrm{LO}$ \\
\hline Final body weight $(\mathrm{g})$ & $463.98 \pm 56.12 \mathrm{a}$ & $460.15 \pm 48.82 \mathrm{ab}$ & $446.48 \pm 49.58 \mathrm{ab}$ & $458.84 \pm 54.39 \mathrm{ab}$ & $441.14 \pm 53.44 \mathrm{~b}$ & $440.99 \pm 56.92 \mathrm{~b}$ \\
Weight gain (\%) & $347.07 \pm 8.09 \mathrm{a}$ & $337.56 \pm 10.43 \mathrm{a}$ & $328.65 \pm 23.70 \mathrm{ab}$ & $342.83 \pm 6.7 \mathrm{a}$ & $310.86 \pm 13.98 \mathrm{~b}$ & $327.55 \pm 4.96 \mathrm{~b}$ \\
Average SGR & $0.68 \pm 0.01 \mathrm{a}$ & $0.68 \pm 0.02 \mathrm{a}$ & $0.66 \pm 0.02 \mathrm{a}$ & $0.67 \pm 0.01 \mathrm{a}$ & $0.62 \pm 0.01 \mathrm{~b}$ & $0.66 \pm 0.01 \mathrm{a}$ \\
Average CI & $1.38 \pm 0.01 \mathrm{a}$ & $1.45 \pm 0.05 \mathrm{ab}$ & $1.45 \pm 0.05 \mathrm{ab}$ & $1.43 \pm 0.07 \mathrm{ab}$ & $1.55 \pm 0.01 \mathrm{~b}$ & $1.46 \pm 0.02 \mathrm{~b}$ \\
\hline
\end{tabular}

*Different letters in the same line denote statistically significant differences $(P<0.05)$. 
Table 3

Identified fatty acids of the muscle of fish fed the experimental diets for 81 days ( $\mathrm{g} / 100 \mathrm{~g}$ fatty acids)

\begin{tabular}{|c|c|c|c|c|c|c|}
\hline & \multicolumn{6}{|l|}{ Diets } \\
\hline & FO & $60 \mathrm{SO}$ & $60 \mathrm{RO}$ & $60 \mathrm{LO}$ & $80 \mathrm{SO}$ & $80 \mathrm{LO}$ \\
\hline $14: 0$ & 5.70 & 3.65 & 3.72 & 3.57 & 2.81 & 2.97 \\
\hline $15: 0$ & 0.31 & n.d. & 0.24 & 0.23 & 0.19 & 0.20 \\
\hline $16: 0$ & 19.14 & 17.42 & 16.29 & 15.78 & 16.36 & 14.79 \\
\hline $16: 1 \mathrm{n}-7$ & 7.76 & 4.88 & 4.89 & 4.80 & 4.07 & 3.92 \\
\hline $16: 2$ & 0.64 & 0.33 & 0.29 & 0.30 & 0.21 & 0.20 \\
\hline $17: 0$ & 0.21 & n.d. & 0.15 & 0.32 & 0.15 & 0.15 \\
\hline $17: 1$ & 0.77 & 0.35 & 0.33 & 0.32 & 0.20 & 0.19 \\
\hline $16: 4 n-3$ & 1.11 & 0.48 & 0.42 & 0.42 & 0.26 & 0.25 \\
\hline 18:0 & 2.81 & 3.00 & 2.54 & 3.00 & 3.08 & 3.07 \\
\hline $18: 1 \mathrm{n}-9$ & 19.69 & 21.49 & 31.86 & 21.22 & 22.25 & 21.75 \\
\hline $18: 1 \mathrm{n}-7$ & 2.86 & 2.27 & 2.74 & 2.09 & 2.16 & 1.86 \\
\hline $18: 1 \mathrm{n}-5$ & 0.20 & n.d. & 0.17 & n.d. & 0.17 & n.d. \\
\hline $18: 2 \mathrm{n}-9$ & 0.33 & 0.24 & 0.25 & 0.21 & 0.18 & 0.15 \\
\hline $18: 2 \mathrm{n}-6$ & 5.53 & 22.47 & 12.82 & 9.87 & 26.97 & 12.54 \\
\hline $18: 2 \mathrm{n}-4$ & 0.32 & n.d. & n.d. & 0.15 & n.d. & n.d. \\
\hline $18: 3 n-6$ & 0.23 & 0.37 & 0.26 & 0.21 & 0.34 & 0.23 \\
\hline $18: 3 n-4$ & 0.22 & n.d. & n.d. & n.d. & n.d. & n.d. \\
\hline $18: 3 n-3$ & 0.93 & 2.34 & 3.37 & 17.29 & 3.13 & 20.16 \\
\hline $18: 4 n-3$ & 1.66 & 1.04 & 0.84 & 1.17 & 0.85 & 1.12 \\
\hline $18: 4 \mathrm{n}-1$ & 0.35 & 0.18 & 0.17 & 0.18 & 0.11 & n.d. \\
\hline $20: 1 \mathrm{n}-9$ & 2.47 & 2.13 & 2.60 & 2.20 & 2.19 & 2.29 \\
\hline $20: 1 \mathrm{n}-7$ & 0.18 & n.d. & n.d. & n.d. & n.d. & n.d. \\
\hline $20: 2$ n-9 & 0.30 & 0.27 & 0.26 & 0.20 & 0.20 & 0.15 \\
\hline $20: 2 n-6$ & 0.24 & 0.38 & 0.32 & 0.23 & 0.49 & 0.27 \\
\hline $20: 3 n-6$ & 0.18 & 0.21 & n.d. & n.d. & 0.20 & n.d. \\
\hline $20: 4 n-6$ & 0.68 & 0.43 & 0.37 & 0.38 & 0.32 & 0.35 \\
\hline $20: 4 n-3$ & 1.02 & 0.67 & 0.62 & 0.73 & 0.47 & 0.68 \\
\hline $20: 5 n-3$ & 9.70 & 4.93 & 4.23 & 4.54 & 3.01 & 3.40 \\
\hline $22: 1 \mathrm{n}-11$ & 1.97 & 1.82 & 1.96 & 1.94 & 2.03 & 2.05 \\
\hline $22: 1 \mathrm{n}-7$ & 0.50 & 0.42 & 0.51 & 0.45 & 0.43 & 0.49 \\
\hline $22: 3 n-6$ & 0.46 & 0.22 & 0.21 & 0.23 & 0.15 & n.d. \\
\hline $22: 5 n-6$ & 0.17 & n.d. & n.d. & n.d. & 0.09 & n.d. \\
\hline $22: 5 n-3$ & 3.00 & 1.79 & 1.63 & 1.72 & 1.25 & 1.23 \\
\hline $22: 6 n-3$ & 8.67 & 6.10 & 6.00 & 6.01 & 4.93 & 5.47 \\
\hline Saturated & 28.51 & 24.39 & 23.01 & 22.86 & 22.92 & 20.95 \\
\hline Monoenoics & 36.15 & 33.42 & 44.94 & 33.08 & 33.57 & 32.48 \\
\hline$n-3$ & 26.23 & 17.35 & 17.22 & 32.40 & 14.08 & 32.84 \\
\hline$n-6$ & 7.16 & 23.94 & 13.91 & 10.85 & 28.66 & 13.56 \\
\hline$n-9$ & 23.12 & 24.12 & 34.97 & 23.81 & 24.88 & 24.15 \\
\hline n-3 HUFA & 22.52 & 13.49 & 12.60 & 13.52 & 9.84 & 11.40 \\
\hline AA/EPA & 0.07 & 0.09 & 0.09 & 0.08 & 0.11 & 0.10 \\
\hline EPA/DHA & 1.12 & 0.81 & 0.71 & 0.76 & 0.61 & 0.62 \\
\hline $\mathrm{OA} / \mathrm{DHA}$ & 2.28 & 3.52 & 5.31 & 3.54 & 4.53 & 3.97 \\
\hline OA/n-3 HUFA & 0.87 & 1.59 & 2.53 & 1.57 & 2.27 & 1.91 \\
\hline$n-3 / n-6$ & 3.72 & 0.72 & 1.24 & 2.99 & 0.49 & 2.42 \\
\hline $\begin{array}{l}\text { Lipid content } \\
\text { (dry weight) }\end{array}$ & 29.47 & 29.60 & 28.63 & 29.94 & 30.91 & 30.79 \\
\hline
\end{tabular}

Table 4

Identified fatty acids of the muscle of fish fed the experimental diets for 204 days $(\mathrm{g} / 100 \mathrm{~g}$ fatty acids)

\begin{tabular}{|c|c|c|c|c|c|c|}
\hline & Diets & & & & & \\
\hline & $\mathrm{FO}$ & $60 \mathrm{SO}$ & $60 \mathrm{RO}$ & $60 \mathrm{LO}$ & $80 \mathrm{SO}$ & $80 \mathrm{LO}$ \\
\hline $14: 0$ & 5.66 & 3.25 & 3.28 & 3.15 & 2.22 & 2.50 \\
\hline $15: 0$ & 0.29 & 0.18 & 0.18 & 0.17 & 0.15 & 0.15 \\
\hline $16: 0$ iso & 0.04 & 0.04 & 0.03 & 0.04 & n.d. & 0.04 \\
\hline $16: 0$ & 19.89 & 17.76 & 16.02 & 16.84 & 17.04 & 15.56 \\
\hline $16: 1 \mathrm{n}-7$ & 8.09 & 4.86 & 4.79 & 4.61 & 3.92 & 3.76 \\
\hline $16: 1 \mathrm{n}-5$ & 0.09 & 0.10 & 0.10 & n.d. & 0.06 & 0.12 \\
\hline $16: 2$ & 0.85 & 0.40 & 0.38 & 0.37 & 0.27 & 0.26 \\
\hline $17: 0$ & 0.22 & 0.16 & 0.15 & 0.16 & 0.15 & 0.14 \\
\hline $17: 1$ & 1.12 & 0.51 & 0.45 & 0.44 & 0.31 & 0.29 \\
\hline $16: 4 n-1$ & 0.07 & 0.06 & 0.05 & 0.06 & 0.09 & 0.08 \\
\hline $16: 4 n-3$ & 1.13 & 0.41 & 0.34 & 0.32 & 0.20 & 0.17 \\
\hline 18:0 & 3.48 & 3.65 & 3.00 & 4.13 & 3.79 & 3.92 \\
\hline $18: 1 \mathrm{n}-9$ & 19.63 & 23.68 & 33.16 & 22.20 & 22.28 & 24.09 \\
\hline $18: 1 \mathrm{n}-7$ & 3.23 & 2.52 & 3.95 & 2.64 & 2.65 & 2.56 \\
\hline $18: 1 \mathrm{n}-5$ & 0.25 & 0.13 & 0.15 & 0.07 & 0.07 & 0.07 \\
\hline $18: 2$ n-9 & 0.33 & 0.17 & 0.26 & 0.16 & 0.13 & 0.11 \\
\hline $18: 2 n-6$ & 5.53 & 23.68 & 12.90 & 10.36 & 28.31 & 12.21 \\
\hline $18: 2 n-4$ & 0.30 & 0.20 & 0.12 & 0.12 & 0.07 & 0.06 \\
\hline $18: 3 n-6$ & 0.23 & 0.34 & 0.22 & 0.16 & 0.30 & 0.15 \\
\hline $18: 3 n-4$ & 0.28 & 0.16 & 0.13 & 0.11 & 0.08 & 0.06 \\
\hline $18: 3 n-3$ & 0.82 & 2.32 & 3.38 & 17.71 & 4.37 & 22.14 \\
\hline $18: 4 n-3$ & 1.31 & 0.66 & 0.60 & 0.76 & 0.49 & 0.71 \\
\hline $18: 4 \mathrm{n}-1$ & 0.36 & 0.18 & 0.15 & 0.17 & 0.10 & 0.12 \\
\hline $20: 0$ & 0.15 & 0.16 & 0.20 & 0.15 & 0.17 & 0.15 \\
\hline $20: 1 \mathrm{n}-9$ & 1.76 & 1.56 & 2.05 & 1.58 & 1.62 & 1.69 \\
\hline $20: 1 \mathrm{n}-7$ & 0.19 & 0.12 & 0.14 & 0.12 & 0.13 & 0.11 \\
\hline $20: 2 n-9$ & 0.31 & 0.23 & 0.33 & 0.22 & 0.19 & 0.16 \\
\hline $20: 2 n-6$ & 0.14 & 0.45 & 0.28 & 0.21 & 0.55 & 0.26 \\
\hline $20: 3 n-6$ & 0.13 & 0.24 & 0.21 & 0.14 & 0.24 & 0.12 \\
\hline $20: 4 n-6$ & 0.53 & 0.31 & 0.30 & 0.31 & 0.26 & 0.23 \\
\hline $20: 3 n-3$ & 0.07 & 0.10 & 0.13 & 0.54 & 0.17 & 0.75 \\
\hline $20: 4 n-3$ & 0.55 & 0.40 & 0.38 & 0.47 & 0.31 & 0.43 \\
\hline $20: 5 n-3$ & 9.07 & 4.07 & 3.57 & 3.48 & 2.44 & 2.31 \\
\hline $22: 0$ & 0.09 & 0.14 & 0.12 & 0.11 & 0.15 & 0.10 \\
\hline $22: 1 \mathrm{n}-11$ & 1.21 & 1.01 & 1.04 & 1.22 & 1.24 & 1.51 \\
\hline $22: 1 \mathrm{n}-7$ & 0.47 & 0.41 & 0.59 & 0.45 & 0.32 & 0.31 \\
\hline $22: 3 n-6$ & 0.44 & 0.18 & 0.17 & 0.17 & 0.13 & 0.11 \\
\hline $22: 4 n-6$ & 0.21 & 0.10 & 0.13 & 0.12 & 0.14 & 0.09 \\
\hline $22: 5 n-6$ & 0.14 & 0.07 & 0.09 & 0.08 & 0.09 & 0.06 \\
\hline $22: 4 n-3$ & 0.08 & 0.05 & 0.06 & 0.06 & 0.08 & 0.04 \\
\hline $22: 5 n-3$ & 3.08 & 1.77 & 1.59 & 1.40 & 1.06 & 0.98 \\
\hline $22: 6 n-3$ & 7.31 & 4.99 & 4.92 & 4.60 & 3.88 & 4.00 \\
\hline Saturated & 29.80 & 25.32 & 22.95 & 24.78 & 23.71 & 22.56 \\
\hline Monoenoics & 36.02 & 33.14 & 46.34 & 33.14 & 32.54 & 31.82 \\
\hline$n-3$ & 23.41 & 14.74 & 14.97 & 29.31 & 12.93 & 31.50 \\
\hline$n-6$ & 7.63 & 25.52 & 14.39 & 11.66 & 30.05 & 13.30 \\
\hline n-3 HUFA & 20.15 & 11.35 & 10.65 & 10.52 & 7.88 & 8.49 \\
\hline AA/EPA & 0.06 & 0.08 & 0.08 & 0.09 & 0.11 & 0.10 \\
\hline EPA/DHA & 1.24 & 0.82 & 0.74 & 0.76 & 0.63 & 0.58 \\
\hline$n-3 / n-6$ & 3.07 & 0.58 & 1.04 & 2.51 & 0.43 & 2.37 \\
\hline $\begin{array}{l}\text { Lipid content } \\
\text { (dry weight) }\end{array}$ & 28.59 & 25.92 & 25.18 & 24.79 & 31.96 & 27.40 \\
\hline
\end{tabular}




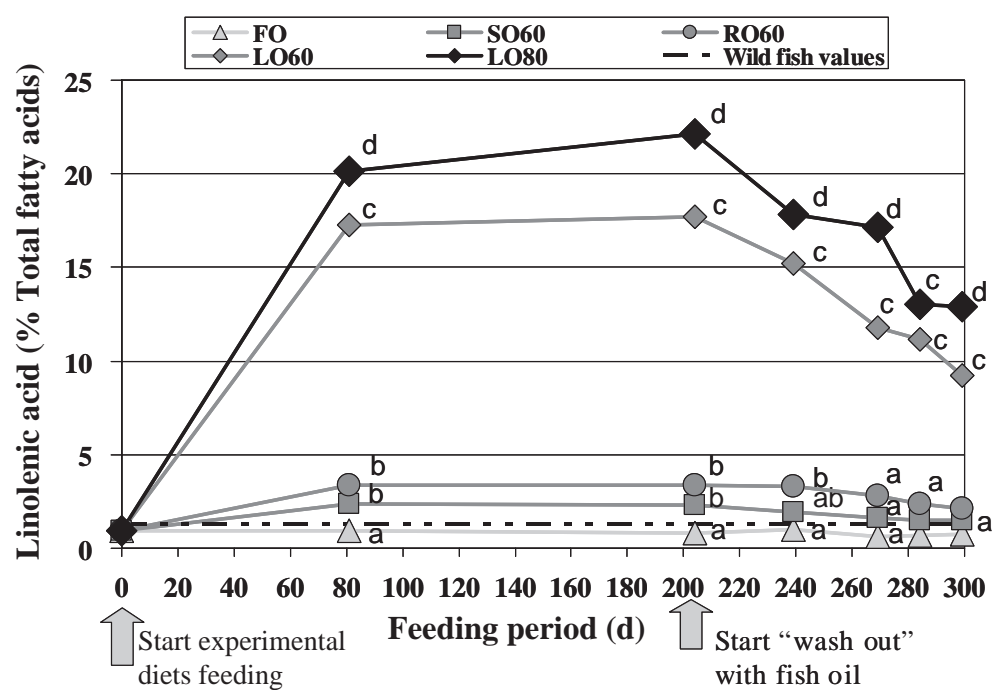

Fig. 2. Effect of feeding vegetable oils followed by fish oil on linolenic acid contents ( $\mathrm{g} / 100 \mathrm{~g}$ fatty acids) of gilthead seabream fillet. Different letters among fatty acid content of fish fillets in a particular day denote significant differences.

and 4, Figs. 4-6). As a consequence of such difference in fatty acid utilization EPA/DHA values were reduced and ARA/EPA increased by the inclusion of vegetable oils along the experiment.

After 204 days of feeding the experimental diets, when fish reached the commercial size, fish oil replacement by vegetable oils affected several sensory attributes in gilthead seabream flesh. Both dietary source of fat and inclusion level showed significant effects, mainly related to appearance and texture characteristics of cooked fillets (Figs. 7 and 8). Principal component analysis of sensorial parameters showed the proximity of flesh characteristics between 60LO and 60RO fish and FO fish, being no significant differences among both groups for any of the parameters studied (Fig. 8). However, elevation of fish oil substitution up to $80 \%$ or dietary soybean oil inclusion significantly affected some sensorial

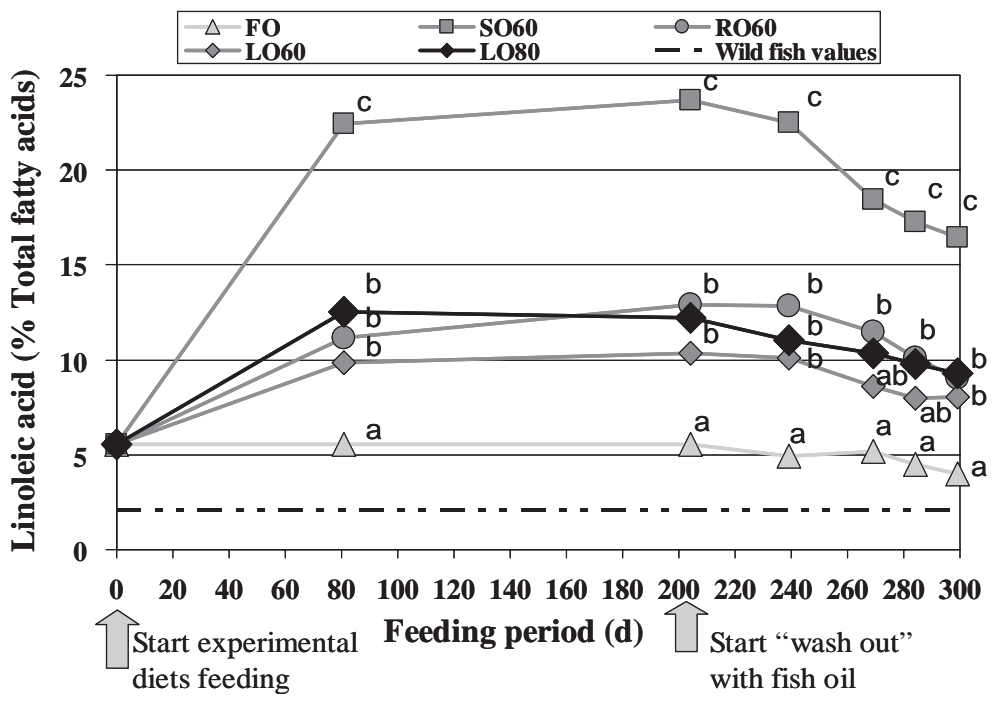

Fig. 3. Effect of feeding vegetable oils followed by fish oil on linoleic acid contents ( $\mathrm{g} / 100 \mathrm{~g}$ fatty acids) of gilthead seabream fillet. Different letters among fatty acid content of fish fillets in a particular day denote significant differences. 


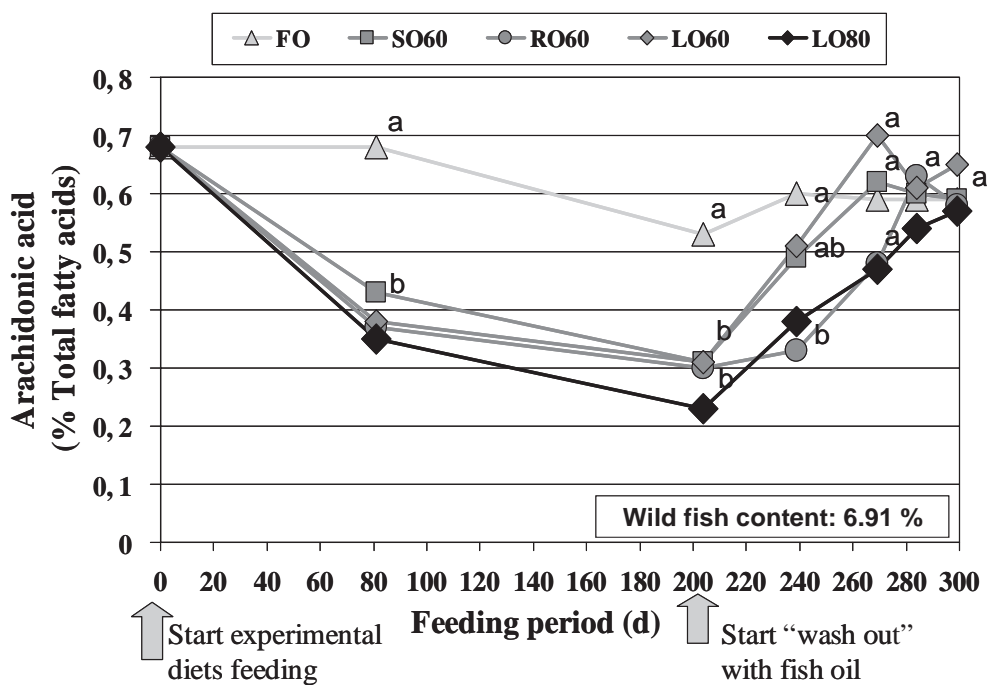

Fig. 4. Effect of feeding vegetable oils followed by fish oil on arachidonic acid contents ( $\mathrm{g} / 100 \mathrm{~g}$ fatty acids) of gilthead seabream fillet. Different letters among fatty acid content of fish fillets in a particular day denote significant differences.

characteristics, giving rise to fillets with overall characteristics farther from that of FO fish (Fig. 8). In comparison with fish fed FO diet, addition of soybean oil in diet produced a significantly less shiny flesh (A-SHI, 41.13 $\pm 6.99,48.44 \pm 6.57$ and $55.73 \pm 4.94$, mean and s.e. for $60 \mathrm{SO}, 80 \mathrm{SO}$ and FO, respectively) but more juicy (T-JUI, 73.06 \pm 4.11 , $67.25 \pm 4.84$ and $52.73 \pm 5.15$ for $60 \mathrm{SO}, 80 \mathrm{SO}$ and FO respectively), less hard in mouth (T-HAR, 19.66 $\pm 4.26 ; 25.63 \pm 4.75$ and $35.40 \pm 6.01$ for $60 \mathrm{SO}$, $80 \mathrm{SO}$ and FO, respectively) and more adhesive (T$\mathrm{ADH}, 20.44 \pm 4.19,18.31 \pm 3.71$ and $29.67 \pm 4.84$ for $60 \mathrm{SO} 80 \mathrm{SO}$ and FO, respectively). Feeding 80LO diet also produced fillets with a slightly lower shininess (A-SHI: 42.38 \pm 5.76 ) than FO fish. Regarding the flavour, only a slightly higher earthy flavour was obtain by soybean inclusion in comparison with FO fish (F-EAR: $5.88 \pm 1.53,3.88 \pm 1.13$

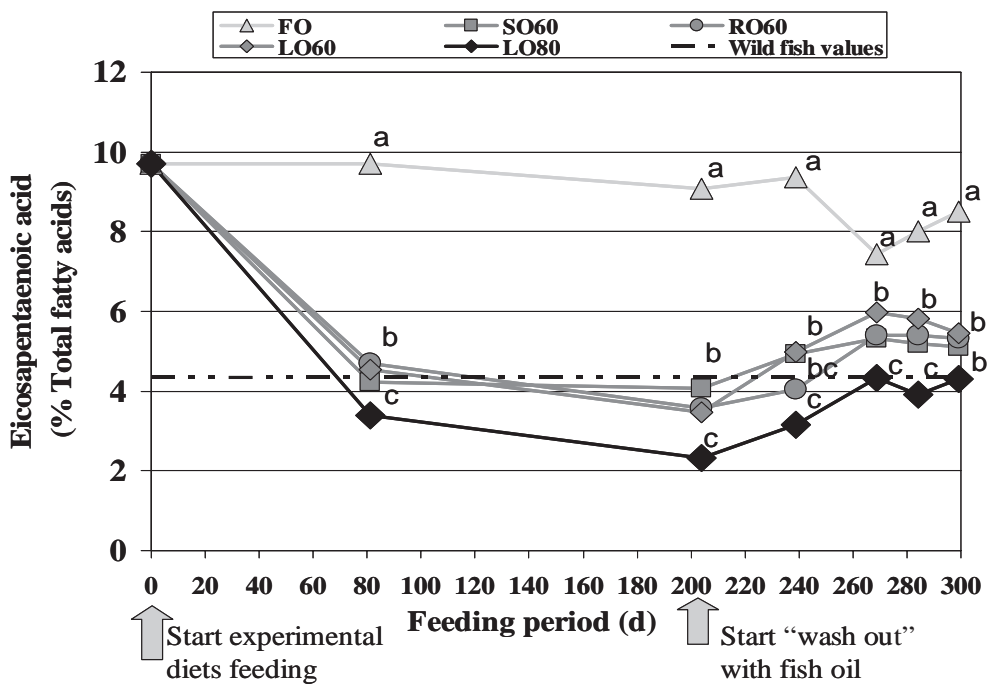

Fig. 5. Effect of feeding vegetable oils followed by fish oil on eicosapentaenoic acid contents ( $\mathrm{g} / 100 \mathrm{~g}$ fatty acids) of gilthead seabream fillet. Different letters among fatty acid content of fish fillets in a particular day denote significant differences. 


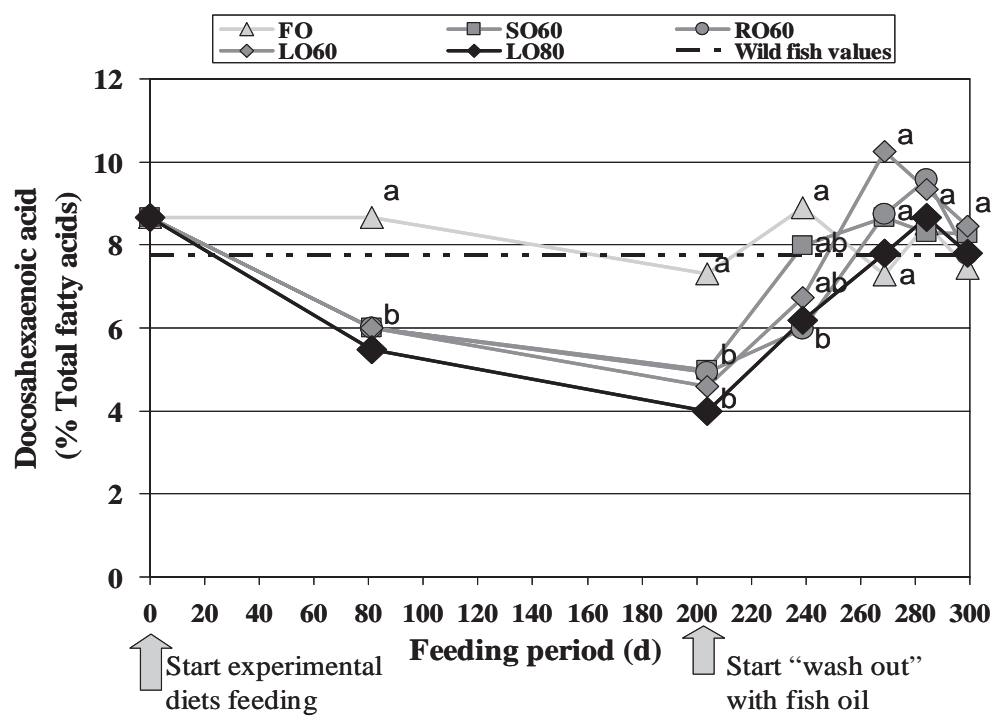

Fig. 6. Effect of feeding vegetable oils followed by fish oil on docosahexaenoic acid contents ( $\mathrm{g} / 100 \mathrm{~g}$ fatty acids) of gilthead seabream fillet. Different letters among fatty acid content of fish fillets in a particular day denote significant differences.

and $2 \pm 0.51$, for $60 \mathrm{SO}, 80 \mathrm{SO}$ and $\mathrm{FO}$, respectively), being values for earthy flavour very low in any case. No significant differences were found in $\mathrm{pH}$ or texture parameters or skin or muscle coloration, except for a significantly lower a and b (Table 5) although these differences were not high enough to show different hue, and a higher chrome value, denoting a higher brightness of the final colour, both in fillet of fish fed diet 80LO (Fig. 7).

Since the fatty acid composition of fish muscle affects its nutritional value for human health a refeeding experiment with fish fed on selected diets was conducted. Even after 90 days re-feeding with a FO diet, 60SO, 60RO, 60LO and 80LO fish muscles showed a reduction in linoleic acid contents of only $30 \%$ of their values after vegetable oil feeding (Fig. 3 ), which was still significantly different than that of fish fed FO diet from the beginning of the experiment. Besides, linoleic acid contents in all experimental fish were higher than those determined in muscle of wild gilthead seabream. Linolenic acid 18:3n-3 was also reduced to $48 \%$ and $42 \%$ of its initial value in fish previously fed diets $60 \mathrm{LO}$ and $80 \mathrm{LO}$ (Fig. 4); values of $\mathrm{FO}, 60 \mathrm{RO}$ and $60 \mathrm{SO}$ fish being close to those of

Table 5

Texture variables $(\mathrm{N}), \mathrm{pH}$ and tristimulus colour characteristics values of raw fillets and skin of fish fed the experimental diets for 204 days

\begin{tabular}{|c|c|c|c|c|c|c|}
\hline & \multicolumn{6}{|l|}{ Diet } \\
\hline & $\mathrm{FO}$ & $60 \mathrm{SO}$ & $60 \mathrm{RO}$ & $60 \mathrm{LO}$ & $80 \mathrm{SO}$ & $80 \mathrm{LO}$ \\
\hline Muscle $\mathrm{pH}$ & $6.09 \pm 0.06$ & $6.09 \pm 0.08$ & $6.12 \pm 0.08$ & $6.10 \pm 0.08$ & $6.17 \pm 0.08$ & $6.12 \pm 0.06$ \\
\hline Whole fish puncture & $11.60 \pm 2.34$ & $11.44 \pm 2.20$ & $14.40 \pm 3.00$ & $11.33 \pm 2.51$ & $12.97 \pm 3.77$ & $12.43 \pm 3.57$ \\
\hline Flesh puncture & $5.69 \pm 1.31$ & $5.68 \pm 1.07$ & $5.87 \pm 1.27$ & $4.69 \pm 1.00$ & $5.30 \pm 0.39$ & $5.91 \pm 0.78$ \\
\hline Flesh compression & $8.94 \pm 3.80$ & $9.09 \pm 2.52$ & $10.03 \pm 2.60$ & $10.44 \pm 2.51$ & $10.40 \pm 3.02$ & $9.68 \pm 3.54$ \\
\hline L (Fillet) & $45.15 \pm 2.49$ & $45.02 \pm 1.38$ & $44.42 \pm 1.47$ & $44.12 \pm 1.43$ & $44.59 \pm 2.21$ & $44.10 \pm 1.30$ \\
\hline a (Fillet) & $-0.01 \pm 0.61 \mathrm{a}$ & $-0.85 \pm 0.28 b$ & $-0.75 \pm 0.38 b$ & $-0.71 \pm 0.40 \mathrm{~b}$ & $-0.89 \pm 0.51 b$ & $-0.98 \pm 0.51 b$ \\
\hline $\mathrm{b}$ (Fillet) & $-1.32 \pm 1.01 \mathrm{a}$ & $-1.88 \pm 0.62 \mathrm{ab}$ & $-1.37 \pm 1.02 \mathrm{a}$ & $-1.88 \pm 0.56 \mathrm{ab}$ & $-2.15 \pm 0.81 b$ & $-2.34 \pm 0.39 b$ \\
\hline L (Skin) & $62.32 \pm 10.18$ & $60.48 \pm 7.92$ & $56.15 \pm 9.23$ & $58.41 \pm 7.10$ & $57.36 \pm 2.58$ & $51.91 \pm 8.45$ \\
\hline a (Skin) & $0.58 \pm 1.15$ & $-0.03 \pm 1.22$ & $-0.29 \pm 1.04$ & $0.62 \pm 0.94$ & $-0.57 \pm 0.73$ & $0.01 \pm 1.38$ \\
\hline b (Skin) & $5.33 \pm 2.2 .76$ & $5.85 \pm 4.32$ & $4.96 \pm 4.01$ & $6.27 \pm 3.71$ & $6.79 \pm 2.61$ & $5.00 \pm 2.43$ \\
\hline
\end{tabular}

L: Lightness; a: Redness; b: Yellowness.

Different letters within the same line denote statistically significant difference $(P<0.05)$. 


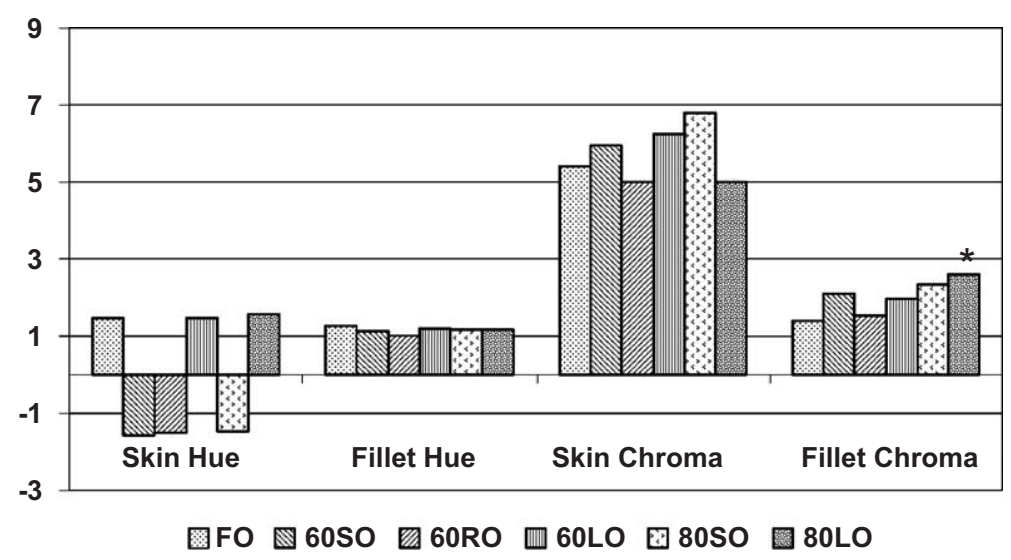

Fig. 7. Effect of long term feeding plant oils on seabream skin and fillet coloration.

wild fish. ARA and DHA levels in fish previously fed vegetable oils progressively increased along re-feeding with FO diet, reaching the values of FO fish after 60 days (Figs. 4 and 6). It was noticeable that wild fish muscle ARA contents were 10 times higher than those of the experimental fish, whereas those of DHA were similar for FO fish and lower for fish fed vegetable oils. EPA contents in muscle of fish fed vegetable oils were similar to those of wild fish but lower than those of FO fish, and only slightly increased along re-feeding, not being recovered even after 90 days (Fig. 5).

\section{Discussion}

The results of this study have shown that it is possible to substitute up to $60 \%$ fish oil by vegetable oils in diets for gilthead seabream without affecting growth and feed utilization even for a long feeding

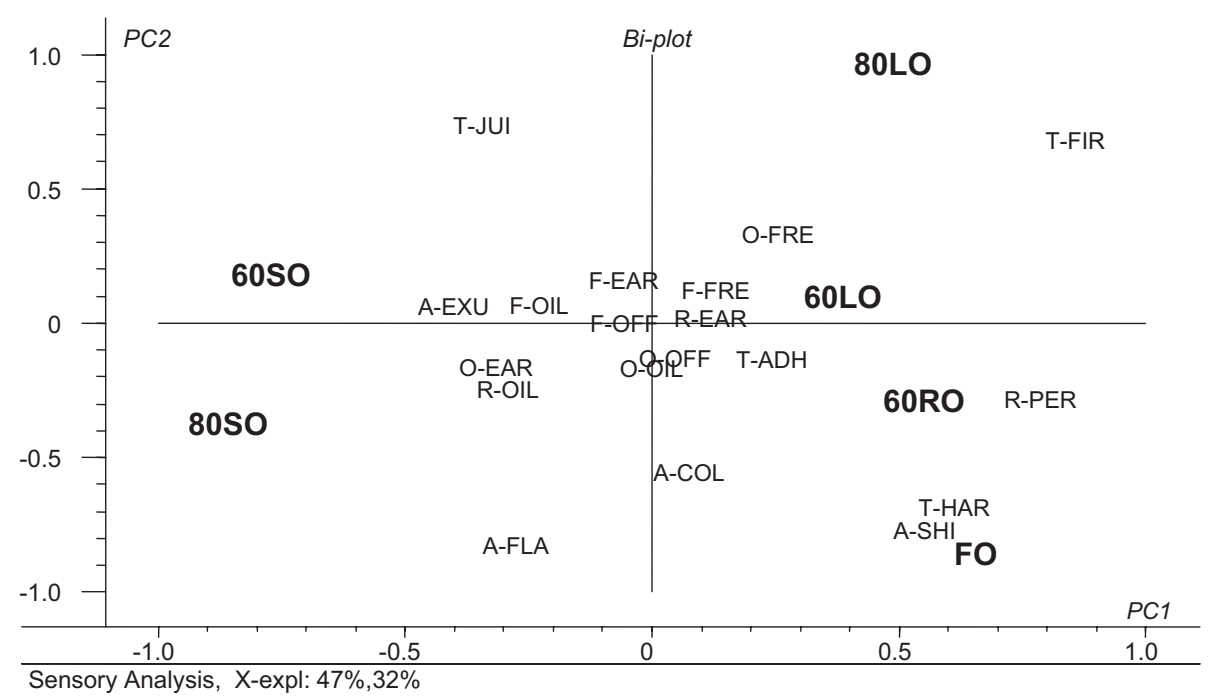

Fig. 8. Scores and loadings of principal component analysis showing distribution of sensory attributes of gilthead seabream after feeding FO or different vegetable oils. Odour (O) freshness (-FRE), earthy (-EAR), off-odour (-OFF) and oily (-OIL); Appearance (A) exuded (-EXU), flaked (-FLA) shininess (-SHI) and colour (-COL); Texture (T) adhesiveness (-ADH), hardness (-HAR), firmness (-FIR) and juiciness (-JUI); Flavour (F) freshness (-FRE), earthy (-EAR), off-flavour (-OFF) and oily (-OIL); Residual taste (R) persistence (-PER), earthy (-EAR) and oily (-OIL). 
period (85-450 g), confirming the results found in previous short term experiments (Izquierdo et al., 2003). These results denoted the lower ability of gilthead seabream to accept vegetable oils in comparison with other marine fish species such as turbot (Regost et al., 2003a). Taking into account that Peruvian anchovy oil, about 3 times richer in n-3 HUFA than capelin oil, was used in the present study, a reduction of $60 \%$ of the fish oil employed in European gilthead seabream feeds would imply a sparing of 27,770 metric tons of fish oil/year (data calculated from FAO, 2003). However, higher reductions in the dietary EFA down to 0.07, 1.12 and 0.69, ARA, EPA and DHA in diet (dry basis, mean $80 \mathrm{SO}$ and $80 \mathrm{LO}$ diets) contents by the $80 \%$ substitution of fish oil significantly reduced growth. Nevertheless, n3 HUFA levels in these two diets were over 1.81 , higher than the minimum inclusion levels $[1.5 \%$ and $1.8 \%$ according to Ibeas et al. (1994) or Montero et al. (1998), respectively] recommended to promote maximum growth and stress resistance in juvenile gilthead seabream fed diets with $12-15 \%$ lipids. Higher dietary lipid levels (Watanabe and Takeuchi, 1989) and a longer feeding trial than in those previous studies may be responsible for the apparently higher requirement of polyunsaturated fatty acids, particularly DHA, in the present experiment.

Feeding vegetable oils reduced muscle contents of DHA and ARA but to a lower extent than could be expected by their reduction in the diet, denoting their importance as essential fatty acids, whereas reduction of EPA in muscle was more pronounced. The reduction in EPA was mainly observed in the neutral lipids (NL) (between 58\% and 69\% EPA reduction in NL and $24 \%$ and $34 \%$ EPA reduction in polar lipids (PL), data not shown), where EPA was higher than DHA in fish fed fish oil. However, in FO fish flesh polar lipids DHA content was double that of EPA and was not reduced by the inclusion of vegetable oils. Moreover, re-feeding with a FO diet for 60 days effectively increased DHA and ARA contents in fillet of fish previously fed with vegetable oils, improving the nutritional value of seabream fillets for human nutrition (Horrocks and Yeo, 1999). But EPA fillet contents were not fully recovered even after 90 days, this fatty acid being also very important for human health, as a potent hypotriglyceridemic factor (Froy- land et al., 1997) and more effective than DHA in inhibiting platelet aggregation (Benistant et al., 1993). In comparison with the evolution of DHA muscle contents, this higher reduction of EPA and lower incorporation after re-feeding with fish oil may be related with several factors. On one hand, it could be due to a preferential oxidation of EPA over DHA in agreement with the higher reduction of EPA in the neutral lipids, since white muscle seem to play a key role in the overall fatty acid oxidation capacity in fish, mitochondrial beta-oxidation dominating over peroxisomal oxidation in this tissue (Froyland et al., 2000), and EPA is mainly oxidized by mitochondria, whereas DHA seems to be oxidized by the peroxisomes and to a lower extent than EPA (Madsen et al., 1998). On the other hand, there is a high affinity of phosphatidylcholine and, especially, phosphatidylethanolamine synthetases for DHA, particularly in the $2 \mathrm{n}$ position, and in gilthead seabream larvae elevation of dietary DHA inhibits EPA incorporation into PE, whereas elevation of dietary EPA levels enhances DHA incorporation into PC and PE (Izquierdo et al., 2000). In agreement with those authors, in the present experiment the elevation of both DHA and EPA enhanced the incorporation of DHA rather than that of EPA.

Higher ARA contents in wild fish in comparison with cultured ones have also been reported previously by some authors (Ohshima et al., 1983). Despite in wild fish there is probably a higher intake of ARA than in cultured fish, coming from the crustaceans, mollusc and occasionally grassy red algae ingested by seabream, the high ARA levels may be also due to a lower oxidation than EPA in wild fish as it has been also shown in cultured fish in the present study.

Despite these changes in muscle fatty acid composition, fish fillets were very well accepted by the panel of judges, in agreement with the preliminary results obtained with gilthead seabream of smaller size (Izquierdo et al., 2003). Reduction in fillet hardness of fish fed diets with soybean inclusion and, particularly, with $80 \%$ fish oil substitution could be related to the lower saturated and higher total polyunsaturated fatty acids contents in muscle. This in turn would also explain the higher juiciness of these fillets in comparison with those of fish fed only fish oil which besides showed the lowest water content, increasing the differences in juiciness. The lower 
juiciness of FO fed fish fillets in comparison with that of fish fed $80 \%$ soybean could be the cause of its higher mouth adhesiveness. This reduction in hardness by the dietary soybean inclusion is in agreement with the results found in brook charr, where lower scores of firmness was observed (Guillou et al., 1995) or in red seabream, where complete substitution of fish oil by soybean oil resulted in a more juicy flesh (Glencross et al., 2003). Atlantic salmon fillet juiciness was also influenced by flesh fatty acid composition (Wagboo et al., 1993). However, organoleptic characteristics of Atlantic salmon flesh were not altered after replacing dietary fish oil by soybean oil (Hardy et al., 1987) or fish meal by full-fat soybean meal (Bjerkeng et al., 1997), which may be related to the shorter feeding periods of these studies, or the higher capacity for dietary linoleic acid utilization by salmon. Although earthy flavour was very low in all experimental fish fillets, inclusion of soybean slightly enhanced this flavour, which is due to the production of different volatile compounds by the action of lipoxygenases on fillet lipids (Milo and Grosch, 1993). These results are in agreement with the more pronounced potatoes odour found in turbot fillets after incorporation of soybean oil in the diet (Regost et al., 2003b). Total replacement of capelin oil by soybean oil sprayed on low-fat dry pellets for Atlantic salmon also affected taste, odour and colour (Thomassen and Rosjo, 1989). Colour alteration caused by $80 \%$ substitution of fish oil by linseed oil, despite significant, was not noticeable by the human eye. Colour shows for the fish either in skin or in muscle is of great importance from the commercial point of view, being directly associated with the product acceptance or rejection by the consumers. Results in present work showed a non effect on coloration by dietary fish oil substitution for vegetable oils in seabream.

However, reduction of n-3 HUFA in fish fillets caused by fish oil substitution may negatively affect their nutritional value for human health. Fish are recognized as one of the most important elements in human nutrition. Its consumption, through the EPA and DHA which fish contain, prevents premature birth and newborn children low weight (Olsen and Secher, 2002), improves depression, schizophrenia and attention deficiency disorders (Small, 2002) and reduces cardiovascular disease risks (Albert et al., 2002;
Rosenberg, 2002). The ingestion of these fatty acids exerts an anti-arrhythmic effect and reduces platelet aggregation and blood triacylglycerides levels (Hu et al., 2002). Thus, health organizations of several countries recommend a daily ingestion of about 1.2-2 $\mathrm{g} / \mathrm{d}$ of $\mathrm{n}-3$ HUFA in order to reduce cardiovascular disease risk, depending on the sex, age and feeding habits of the patient. According to the results of the present study, the ingestion of about 120 or $250 \mathrm{~g}$ of gilthead seabream fed the fish oil based diet (FO) or a $60 \%$ fish oil substituted diet (60SO, 60RO and 60LO) would be enough to cover the daily recommended ingestion of EPA and DHA in contrast with the $600 \mathrm{~g}$ of wild gilthead seabream necessary to supply that EFA, denoting the high nutritional value of farmed seabream.

In addition, the introduction of certain fatty acids of vegetal origin such as $\alpha$-linolenic acid in a Mediterranean diet reduces the number of cardiac deaths by $70 \%$ (De Lorgeril et al., 1994, 1999), as well as cardiovascular and overall mortality rates (Singh et al., 2002). Despite its importance in human nutrition there are very few food items rich in this fatty acid and its presence in fish fillets would add an extra nutritional value. Inclusion of rapeseed oil raised fish fillets monounsaturated fatty acids contents, whose increase in human diet enhance endothelium dependant vasodilatation in hypercholesterolemic men (Fuentes et al., 2001), reducing LDL cholesterol and preventing atherosclerosis. On the contrary, several authors claim that high levels of n- 6 fatty acids present in some vegetal oils and the unbalance in the dietary $n-3 / n-6$ fats induce arrhythmic which subsequently originate heart strokes (Jouven et al., 2001; Leaf, 2001). In this sense, the present study has shown that fish fillets of seabream fed during the on-growing period with soybean oil is boosted with linoleic acid even after a terminal feeding of 90 days with a diet containing fish oil as a single lipid source, denoting the persistence of linoleic acid in fish muscle.

In conclusion, the results of this study suggest that it is possible to substitute up to $60 \%$ fish oil by vegetable oils in diets for gilthead seabream without affecting growth and feed utilization even for a long feeding period. Muscle DHA and ARA contents are reduced but recovered after 60 days of feeding a fish oil diet, whereas EPA muscle contents are not only 
reduced in a higher extent but are not recovered after 90 days of feeding fish oil. Despite these changes in muscle fatty acid composition, fish fillets remained being highly nutritious for human health and very well accepted by the panel of judges.

\section{Acknowledgements}

Acknowledge is due to European Union under "Quality of Life and Management of Living Resources" through the project Q5RS-2000-30058 "RAFOA", which partly (4 diets) granted the research, and the Spanish government under FEDER program, project no. 1FD1997-1774 which granted the rest of them.

\section{References}

Ackman, R.G., 2001. Fish is more than a brain food. IIFET 2000 Proceedings. $10 \mathrm{pp}$.

Albert, C.M., Campos, H., Stampfer, M.J., Ridker, P.M, Manson, J.E., Willett, W.C., Ma, J., 2002. Blood levels of long-chain n-3 fatty acids and the risk of sudden death. N. Engl. J. Med. 346, 1113-1118.

Alexis, M.N., 1997. Fish meal and oil replacers in Mediterranean marine fish diets. In: Tacon, A., Basurco, B. (Eds.), Feeding Tomorrow's Fish, pp. 183-204.

Bell, J.G., McEvoy, J., Tocher, D.R., McGhee, F., Campbell, P.J., Sargent, J.R., 2001. Replacement of fish oil with rapeseed oil in diets of Atlantic salmon (Salmo salar) affects tissue lipid composition and hepatocyte fatty acid metabolism. J. Nutr. 131, $1535-1543$

Benistant, C., Achard, F., Marcelon, G., Lagarde, M., 1993. Platelet inhibitory functions of aortic endothelial cells: effects of eicosapentaenoic and docosahexaenoic acids. Atherosclerosis 104, 27-35.

Bjerkeng, B., Refstie, S., Fjalestad, K.T., Storebakken, T., Rødbotten, M., Roem, A.J., 1997. Quality parameters of the flesh of Atlantic salmon (Salmo salar) as affected by dietary fat content and full-fat soybean meal as a partial substitute for fish meal in the diet. Aquaculture 157, 297-309.

Borderías, A.J, Lamua, M., Tejada, M., 1983. Texture analysis of fish fillets and minced fish by both sensory and instrumental methods. J. Food Technol. 18, 85-95.

Caballero, M.J., 2002. Absorción, transporte y utilización de los lípidos dietéticos en el intestino e hígado de dorada (Sparus aurata) y lubina (Dicentrarchus labrax). Doctoral thesis. University of Las Palmas de Gran Canaria.

Caballero, M.J., Obach, A., Rosenlund, G., Montero, D., Gisvold, M., Izquierdo, M.S., 2002. Impact of different dietary lipid sources on growth, lipid digestibility, tissue fatty acid compo- sition and histology of rainbow trout, Oncorhynchus mykiss. Aquaculture 214, 253-271.

Christie, W.W., 1982. Lipid Analysis. Pergamon Press, Oxford.

CIE, 1976. Colorimetry. Commission Internationale de l'Eclairage, vol. 15. CIE Publication, Paris.

De Lorgeril, M., Renaud, S., Mamelle, N., Salen, P., Martin, J.L., Monjaud, I., Guidollet, J., Touboul, P., Delaye, J., 1994. Mediterranean alpha-linolenic acid-rich diet in secondary prevention of coronary heart disease. Lancet 343, 1454-1459.

De Lorgeril, M., Salen, P., Martin, J.L., Monjaud, I., Delaye, J., Mamelle, N., 1999. Mediterranean diet, traditional risk factors, and the rate of cardiovascular complications after myocardial infarction: final report of the Lyon Diet Heart Study. Circulation 99, 779-785.

Folch, J., Lees, M., Sloane-Stanley, G.H., 1957. A simple method for the isolation and purification of total lipids from animal tissues. J. Biol. Chem. 226, 497-509.

Froyland, L., Madsen, L., Vaagenes, H., Totland, G., Auwerx, J., Kryviv, H., Staels, B., Berge, R., 1997. Mitochondrion is the principal target for nutritional and pharmacological control of triglyceride metabolism. J. Lipid Res. 38, 1851-1858.

Froyland, L., Lie, O., Berge, R.K., 2000. Mitochondrial and peroxisomal beta-oxidation capacities in various tissues from Atlantic salmon Salmo salar. Aquac. Nutr. 6, 85-89.

Fuentes, F., López-Miranda, J., Sánchez, E., Sánchez, F., Páez, J., Paz-Rojas, E., Marín, C., Gómez, P., Jiménez-Pérez, J., Ordovás, J., Pérez-Jiménez, F., 2001. Mediterranean and lowfat diets improve endothelial function in hypercholesterolemic men. Ann. Intern. Med. 134, 1115.

Ginés, R., Palicio, M., Zamorano, M.J., Argüello, A., López, J.L., Afonso, J.M., 2002. Starvation before slaughtering as a tool to keep freshness attributes in gilthead sea bream (Sparus aurata). Aquac. Int. 10, 379-389.

Glencross, B.D., Hawkins, W.E., Curnow, J.G., 2003. Restoration of the fatty acid composition of red seabream (Pagrus auratus) using a fish oil finishing diet after grow-out on plant oil based diets. Aquac. Nutr. 9, 409-418.

Guillou, A., Soucy, P., Khalil, M., Adambounou, L., 1995. Effects of dietary vegetable and marine lipid on growth, muscle fatty acid composition and organoleptic quality of flesh of brook charr (Salvelinus fontinalis). Aquaculture 136, $351-362$.

Hardy, R.W., Scott, T.M., Harrell, L.W., 1987. Replacement of herring oil with menhaden oil, soybean oil, or tallow in the diets of Atlantic salmon raised in marine net-pens. Aquaculture 65, $267-277$.

Hardy, R.W., Higgs, D.A., Lalla, S.P, Tacon, A.G.J., 2001. Alternative dietary protein and lipid sources for sustainable production of salmonids. Fisken-Havet 8, $44 \mathrm{pp}$.

Herold, P.M., Kinsella, J.E., 1986. Fish oil consumption and decreased risk of cardiovascular disease: a comparison of findings from animal and human feeding trials. Am. J. Clin. Nutr. 43, 566-598.

Horrocks, L.A., Yeo, Y.K., 1999. Health benefits of docosahexaenoic acid (DHA). Pharmacol. Res. 40, 211-225.

Hu, F.B., Bronner, L., Willett, W.C., Stampfer, M.J., Rexrode, K.M., Albert, C.M., Hunter, D., Manson, J.E., 2002. Fish and 
omega- 3 fatty acid intake and risk of coronary heart disease in women.. JAMA 287, 1815-1821.

Hwang, D., 1989. Essential fatty acids and immune responses. FASEB J. 3, 2052-2061.

Ibeas, C., Izquierdo, M.S., Lorenzo-Hernandez, A., 1994. Effect of different levels of n-3 highly unsaturated fatty acids on growth and fatty acid composition of juvenile gilthead seabream (Sparus aurata). Aquaculture 127, 177-188.

International Organization for Standardization (ISO), 1985. Sensory analysis - methodology — general guidance. ISO, Geneva, Switzerland. ISO 6658:1985.

International Organization for Standardization (ISO), 1988. Sensory analysis - general guidance for the design of test rooms. ISO, Geneva, Switzerland. ISO 8589:1988(E).

International Organization for Standardization ISO, 1993. Sensory analysis - general guidance for the selection, training and monitoring of assessors: Part 1. Selected assessors. ISO, Geneva, Switzerland. ISO 8586-1:1993.

Izquierdo, M.S., Watanabe, T., Takeuchi, T., Arakawa, T., Kitajima, C., 1990. Optimum EFA levels in Artemia to meet the EFA requirements of red sea bream (Pagrus major). In: Takeda, M., Watanabe, T. (Eds.), The Current Status of Fish Nutrition in Aquaculture. Tokyo Univ. Fisheries, Tokyo, pp. 221-232.

Izquierdo, M.S., Socorro, J., Arantzamendi, L., Hernandez-Cruz, C.M., 2000. Recent advances in lipid nutrition in fish larvae. Fish Physiol. Biochem. 22, 97-107.

Izquierdo, M.S., Obach, A., Arantzamendi, L., Montero, D., Robaina, L., Rosenlund, G., 2003. Dietary lipid sources for seabream and seabass: growth performance, tissue composition and flesh quality. Aquacult. Nutr. 9, 397-407.

Jouven, X., Charles, M.A., Desnos, M., Ducimetière, P., 2001. Circulating nonesterified fatty acid level as a predictive risk factor for sudden death in the population. Circulation 104, $756-761$.

Leaf, A., 2001. Plasma nonesterified fatty acid concentration as a risk factor for sudden cardiac death: the Paris prospective study. Circulation 104, 744-745.

Madsen, L., Froyland, L., Dyroy, E., Helland, K., Berge, R.K., 1998. Docosahexaenoic and eicosapentaenoic acids are differently metabolized in rat liver during mitochondria and peroxisome proliferation. J. Lipid Res. 39, 583-593.

Milo, C., Grosch, W., 1993. Changes in the odorants of broiled trout (Salmo salar) as affected by the storage of the raw material. J. Agric. Food Chem. 41, 2076-2081.

Montero, D., Tort, L., Izquierdo, M.S., Robaina, L., Vergara, J.M., 1998. Depletion of serum alternative complement pathway activity in gilthead seabream caused by alpha-tocopherol and n-3 HUFA dietary deficiencies. Fish Physiol. Biochem. 18, 399-407.

Montero, D., Kalinowski, T., Obach, A., Robaina, L., Tort, L., Caballero, M.J., Izquierdo, M.S., 2003. Vegetable lipid sources for gilthead seabream (Sparus aurata): effects on fish health. Aquaculture 225, 353-370.
Morris, C.A., Haynes, K.C., Keeton, J.T., Gatlin, D.M., 1995. Fish oil dietary effects on fatty acid composition and flavor of channel catfish. J. Food Sci. 60, 1225-1227.

NRC (National Research Council), 1993. Nutritional requirements of fish. National Academic Press, Washington DC, US, pp. 114.

Ohshima, T., Wada, S., Koizumi, C., 1983. Comparison of lipids between cultured and wild seabreams. Bull. Jpn. Soc. Sci. Fish 49 (9), 1405-1409.

Olsen, S.F., Secher, N.J., 2002. Low consumption of seafood in early pregnancy as a risk factor for preterm delivery: prospective cohort study. Br. Med. J. 324, 1-5.

Regost, C., Arzel, J., Robin, J., Roselund, G., Kaushik, J., 2003a. Total replacement of fish oil by soybean oil with return to fish oil in turbot (Psetta maxima): I. Growth performance, flesh fatty acid profile, and lipid metabolism. Aquaculture 217, 465-482.

Regost, C., Arzel, J., Cardinal, M., Rosenlund, G., Kaushik, S.J., 2003b. Total replacement of fish oil by soybean oil with return to fish oil in turbot (Psetta maxima): II. Flesh quality properties. Aquaculture 220, 737-745.

Rosenberg, I.H., 2002. Fish: food to calm the heart. N. Engl. J. of Med. 346, 1102-1103.

Rosenlund, G., Obach, A., Sandberg, M.G., Standal, H., Tveit, K., 2001. Effect of alternative lipid sources on long-term growth performance and quality of Atlantic salmon (Salmo salar L.). Aquacult. Res. 32, 323-328.

Singh, R.B., Dubnov, G., Niaz, M.A., Ghosh, S., Singh, R., Rastogi, S.S., Manor, O., Pella, D., Berry, E.M., 2002. Effect of an Indo-Mediterranean diet on progression of coronary artery disease in high risk patients (Indo-Mediterranean Diet Heart Study): a randomised single-blind trial. Lancet 360 , $1455-1461$.

Small, M.F., 2002. The happy fat. New Sci. 175, 34-37.

Sokal, R.R., Rolf, S.J., 1995. Biometry. The Principles and Practice of Statistics in Biological Research, 3rd edition. W.H. Freeman and Company, New York, pp. 419.

Thomassen, M.S., Røsjø, C., 1989. Different fats in feed for salmon: Influence on sensory parameters, growth rate and fatty acids in muscle and heart. Aquaculture 79, 129-135.

Wagboo, R., Sadnes, K., Torrisen, O.J., Sandvin, A., Lie, O., 1993. Chemical and sensory evaluation of fillets from Atlantic salmon (Salmo salar) fed three levels of $n-3$ polyunsaturated fatty acids at two levels of vitamin E. Food Chem 46, 361-366.

Watanabe, T., 2002. Strategies for further development of aquatic feeds. Fisheries Sci. 68, 242-252.

Watanabe, T., Takeuchi, T., 1989. Implications of marine oils and lipids in aquaculture. In: Ackman, R.G. (Ed.), Marine Biogenic Lipids, Fats and Oils, vol. II. CRC Press, Boca Ratón, Fl, pp. 457-479.

Wyszecki, G., Stiles, W.S., 1982. Color Science. Concepts and methods, quantitative data and formulae. Willey-Interscience Publication, New York, 950 pp. 